\title{
The Passion Pay: Exploring Practices of Talent Exploitation
}

\author{
Yongseok JANG ${ }^{1}$, Woo Jin LEE ${ }^{2}$
}

Received: August 01, 2020 Revised: September 06, 2020 Accepted: September 10, 2020

\begin{abstract}
This inductive study seeks to establish a conceptual background for theoretical development regarding talent misuse in the context of small and medium-sized enterprises (SME). The two objectives for the goal were (1) to explore and build a list of unethical treatment practiced on young talents; (2) to establish new framework for the special context or refining the existing framework on employee mistreatment. For the first goal, an attempt was made to develop a list of mistreating behavior by collecting and analyzing cases of ethical disputes. Analyses on 64 cases of talent mistreatment, namely 'passion pay', was conducted to present a conceptual ground for further investigation. Then, for the second objective, this study has proposed an integrative approach for assessing these ethical elements. The ethical implications were discussed based on an assessment conducted using three theories of ethics. Finally, a cluster analysis further shows the emergence of three groups based on the mistreating behaviors. We observed seven different mistreatment behaviors under four categories of mistreatment practices. Additionally, the cluster analysis results imply that talent mistreatment may be rooted in work characteristics. Organizational size may provide some contextual reasoning, but the extent to which this factor interacts with work characteristics left unclear.
\end{abstract}

Keywords: SMEs, Work Characteristics, Passion Pay, Talent Mistreatment

JEL Classification Code: M100, M130, M140, J710

\section{Introduction}

In South Korea, misusing human resources has become prevalent among businesses. For employers, this unfortunate situation has become an opportunity to exploit young talent as cheap labor on a short-term basis, which increases their flexibility to hire and fire these employees while also lowering costs. This practice is now known as "passion payment" (or passion pay in short), referring to the reality that "apprentices are supposed to be passionate enough to put up with poor treatment" (Passion Pay, 2015), according to Jang (2016). For example, a prominent young designer, Lie Sangbong, hired interns at little to no pay and no overtime compensation. Lie

\footnotetext{
${ }^{1}$ First Author. Assistant Professor, Department of Management, California State University San Bernardino, USA.

E-mail: yongseok.jang@csusb.edu

${ }^{2}$ Corresponding Author. Assistant Professor, Graduate School of Global Entrepreneurship, Kookmin University, Korea [Postal Address: 77, Jeongneung-ro, Seongbuk-gu, Seoul, 02707, Korea] Email: drlee@kookmin.ac.kr

(c) Copyright: The Author(s)

This is an Open Access article distributed under the terms of the Creative Commons Attribution Non-Commercial License (https://creativecommons.org/licenses/by-nc/4.0/) which permits unrestricted non-commercial use, distribution, and reproduction in any medium, provided the original work is properly cited.
}

was forced to publicly apologize. WeMakePrice, a popular Korean social commerce business fired 11 merchandising assistants after a two-week probationary period (Lee, 2015). At the time of hiring, these employees were hired under the condition that they would successfully complete a two-week probationary period, during which they would receive a daily wage. Similar to how consumers test products and return them if not satisfied, WeMakePrice fired these employees after the trial period. The consequence was expensive. In the first day following breaking news regarding the case, 32,000 accounts were deactivated, according to Korea Times (Park, 2015). The company decided to reinstate the 11 interns after facing severe public backlash, but the damage to its brand image was irrevocable. These cases fall into the general category of "intern exploitation," a term that, in the U.S., usually refers to unpaid internships.

Besides severe backlash businesses have to deal with, the cases reveal lack of understanding on why it happens, which further reveals how to best safeguard the business from such mistake. While existing frameworks such as workplace mistreatment, or organizational justice do provide some insights, but falls short of addressing unique circumstances defined by probationary status. As an academic response, this study seeks to establish a conceptual background for 
theoretical development regarding talent misuse in the context of entrepreneurial ventures. To achieve this purpose, this study provides an explorative study with an aim to build a list of the unethical treatments experienced by young talent to highlight special attributes associated with them in the context of entrepreneurial ventures. Second, this study will create a new framework or refine the existing framework for the special context of employee mistreatment for employee during the probationary period.

This study's primary contribution is to advance the understanding of talent mistreatment in the context of SMEs. In particular, this explorative study seeks to expand the horizons of the existing framework (Harlos and Pinder's model). The observations of this study indicate that four types of employee mistreatment are still generally applicable but require modification to be inclusive of SMEs. This study's secondary contribution is paying special attention to interns or young talent, whose voices are not often heard. Employee mistreatment was studied based on institutionalized methods of making voices heard, such as complaints collected in the form of grievances (Boswell \& Olson-Buchanan, 2004; Olson-Buchanan \& Boswell, 2008). However, interns or young talent lack access to such methods so early in their careers, and thus have no way of being heard.

First, we provide three ethical theories to conduct evaluative studies for a given recruiting approach. Using 64 cases collected from the U.S. and South Korea, an explorative study will be presented to show statistical association between mistreating practices and the contexts. After presenting the analysis, and the results, the paper concludes with a discussion and the implications of the findings, the limitations, and potential topics for future research.

\section{Theoretical Foundation}

Business ethicists have developed various frameworks to assess business decision-making using different foundational principles (e.g., motives, virtue, rights, rules, utility, justice, duty, social obligations, etc.). These frameworks are characterized as being either deontological or teleological (Brady \& Dunn, 1995), wherein the former focuses on the righteousness of specific actions or behaviors, and the latter examined the net positives and negatives embedded in the consequences of an action.

The deontological framework defines ethical behaviors in terms of obligations, rights, principles, rules, or codes (Whetstone, 2001) when fulfilling one's moral duty (Weisberg Pfleiger, \& Friedberg, 2007). An individual must place fulfilling his/her duty before his/her self-interest (Weisberg et al, 2007). Therefore, rights are subordinate to the notion of obligation (Weil, 2003). While there may be duties that are conducted independent of any individual's rights, one's duty generally obligates one to act in observance of those rights (Brady \&Dunn, 1995). While the concept of moral duty correlates with "moral rights," this framework fails to discuss specific moral rights (Lahdesmaki, 2005). Moreover, the Kantian perspective does not provide guidance on how to resolve or balance conflicting rights (Velasquez, 2002). Thus, it is problematic to build a system to guide action, given the innumerable cases of conflict among universal morality rules. As illustrated by Hunt and Vitell (1986), lying is unethical in terms of deontology as it is a violation of universal moral standards; however, it could be argued that lying could, in certain cases, protect people from being hurt.

A second framework, utilitarianism, adopts a teleological perspective. The primary focus here is the value of the consequences of an act, i.e., the action must be beneficial based on its ends, rather than its means (Bradburn, 2001). Thus, an act is righteous when it produces the greatest net benefits. Therefore, this perspective e allows for situational ethics, where the resulting contributions of an action to particular circumstances are important considerations for assessing the utility of the action. Unequal treatment of the same action is justified if it maximizes general welfare (Airaksinen, 1987). The maximized benefit must not be for the actor but for the individuals affected by the action (Lahdesmaki, 2005), giving rise to the notion of altruism. In this regard, benefits can be defined in various forms, such as the absence of pain or presence of pleasure. The main drawback of the utilitarian framework is the difficulty in objectively measuring the relative benefits of a consequence (Lahdesmaki, 2005). While a utilitarianist would attempt to capture both the intensity and duration of each benefit associated with an action (Häyry, 1999), in reality, consequences are usually a nuanced hybrid, i.e., a mixture of good and bad, and require subjective interpretation. Besides, the utilitarian view tends to remain blind to the clearly unethical actions posed by companies when negative consequences are not clearly perceived or properly weighed.

A third perspective is provided by the virtue-based framework (VBF). The VBF focuses on personal moral virtues (courage, honesty, fairness, fidelity, goodwill, etc.) in different contexts. The focal point of ethical assessment becomes whether a particular action promotes the development of good moral character, thus leading to a better way of life (Duncan, 1995; Katz, 2011). Righteous action is not pre-defined based on objective measures, but rather, emerges from engagements where individuals are willing to influence one another to find virtuous ways that fit the context they share (Ladkin, 2006). Ethicality is judged by the extent to which a chosen action contributes to the promotion of virtuous human character. Virtue-based ethics also has its shortcomings. Different individuals may not use the same mechanisms to interpret the ethics of a given action. As such, specific linkages between virtues and ethics can be difficult to establish. Additionally, the importance and interpretation 
of a given virtue can vary based on one's cultural background, which can be problematic when individuals from different cultural milieus work together and must agree upon the judgment of some action (Velasquez, 2000).

In short, while deontology and utilitarianism are based on the objectivity and universality of morality (obedience to the moral absolute for deontology, and objective agreement/ measurement of happiness for utilitarianism), the VBF adopts a relational concept of morality. The following section will discuss how explorative insights into talent mistreatment were obtained in this study.

\section{Literature Review}

In this section, we provide a brief overview of ongoing scholarly debate over the natures of interactional mistreatment. For regular employees, scholars build theories on the belief that workplace mistreatment is an interpersonal event. The most popular approach is to focus on the dynamics of individual's relationships. Focusing on individual's behavior, work place mistreatment is viewed as a series of undesirable human activities occurring from interpersonal relations. Under this perspective, mistreatment may take place in the following forms: blatant or subtle harassment, stereotyping, prejudice, discrimination, ethnocentrism as well as intergroup conflict. Defining such actions as 'workplace aggression', interpersonal conflict is considered a legitimate source of employee mistreatment caused by perpetrators with certain personality, a minority status (Karakowsky \& Siegel, 1999), high job insecurity (Zapf \& Einarsen, 2011), high role conflict (Rizzo, House, \& Lirtzman, 1970), role ambiguity (Jennifer, Cowie, \& Ananiadou, 2004) or of using certain power bestowed upon an individual. The alternative to that is to pay attention to the dynamics of both sides, including characteristics of targets (i.e. low self-esteem as found in Agervold \& Mikkelsen, (2004)), to mainly overcome drawback of 'perpetrator focused view', namely 'dual approach' (i.e., Samnani \& Singh, 2016). Nevertheless, work place mistreatment is still portrayed as interpersonal issue. Table 1 summarizes the key variables and the literatures.

Table 1: Literatures in Interpersonal Conflict

\begin{tabular}{|l|l|}
\hline Key Variables & \multicolumn{1}{|c|}{ Literatures } \\
\hline Low Self-esteem & Agervold \& Mikkelsen, 2004 \\
\hline Minority Status & Karakowsky \& Siegel, 1999 \\
\hline High Job Insecurity & Zapf \& Einarsen, 2011 \\
\hline High Role Conflict & Rizzo, House, \& Lirtzman, 1970 \\
\hline Role Ambiguity & Jennifer, Cowie, \& Ananiadou, 2004 \\
\hline
\end{tabular}

While we know that talent mistreatment is quite comprehensively applicable, we would like to focus on the more specific context. First, we pay particular attention to the linkage between talent mistreatment and the context of entrepreneurship. Compared to much attention given to organizational culture, the link between organizational strategy and ethical practice has not been fully explored. Second, this study extends attention to those on the border of a formal hiring status, such as those newly hired within a probation period or interns. Interns or probationary periods provide a defenseless status where individuals feel weakness, a lack of confidence or confusion, which may attract bullying behavior from individuals taking higher power position (Zarf \& Einarsen, 2011). While other types of workplace mistreatment are obviously unethical, we take caution at this pilot stage as one might argue them (distributive, procedural and systematic) as consent-based actions.

If we look at the definition of employee mistreatment, such a view is well reflected: the acts that 'harm the target and which the target is motivated to avoid' (Hershcovis $\&$ Reich, 2013). There may be grounds for the argument that consensus becomes a sufficient condition, an example of which might be a contractual binding between business organizations. A critical assumption here is that they are both informed and one party is free from the influence of the other, which is clearly violated in the context of early career recruits and employers. This then raises the question: What legitimate bases can we establish to assert an action to be unethical? We believe answering such questions requires more comprehensive dataset with more systematic approach. In this sense, we hope this pilot study successfully draws academic attention that could lead us to second stage in the future to deal with other dimensions of talent mistreatments. In the following section, we continue to explain how we access and collect such special samples to conduct this unique inquiry.

\section{Empirical Approach}

\subsection{Sampling Strategy and Data Preparation}

For the purpose of the study, we employed an inductivedeductive approach, with an aim to generate insight into the reasoning of what is being practiced in the field. The inductive-deductive strategy allows us first to initiate the search of mistreating behaviors derive from existing studies (Patton, 2001; Merriam and Tisdell, 2015). Then, it still opens to emergence of unobserved categories from the data collected from uncharted field, the interactional behaviors imposed upon individuals gone through a probationary period. As a first step, it was necessary to first build a list of cases in which talent mistreatment currently occurs. The data collection process involved multiple tasks of field 
research using diverse sources including practitioners, civic organizations for labor issues, labor lawyers, labor unions, and/or government organizations. To develop a preliminary list of talent misuse cases, a total of 64 cases, including 26 SMEs and 38 established companies, were collected from numerous sources, such as news reporters, law offices, and bloggers. Primarily, text analysis was utilized to find out what kind of mistreating behaviors are present in practice.

As a way of standardizing the qualitative data, variables were created in only a binary format, wherein 1 indicates presence and 0 indicates absence of mistreating behavior. Hence, while the analysis still falls short of addressing the magnitude of stress, it allows the acknowledgment of the presence of mistreatment. After completing the case collection, a comprehensive framework for workplace mistreatment, presented by Harlos and Pinder (1999), was borrowed to build a list of mistreatment behavior. The framework delineates mistreatment behavior into four different categories. The first type is interactional mistreatment, referring to actions occurring between personnel but mostly from authority figures. The second type, distributive mistreatment, refers to negative practices stemming from a lack of access to resources. The third type, procedural mistreatment, refers to problems rooted in unfair policies and procedures (Kim, \& Lee, 2020). Finally, systemic mistreatment, is related to unfair systems within the larger organization (Meares, Oetzel, Torres, Derkacs, \& Ginossar, 2004). Based on this framework, Table 2 provides a list of mistreatment behaviors observed in the sample cases.

The next step was to build a list of work characteristics that could potentially be related to mistreatment. The "Work Design Questionnaire (WDQ)" was utilized as a measurement framework. While the sample cases did not provide all necessary information required by the framework because they were not designed based on the WDQ, they repeatedly reported information relevant to three major categories of the WDQ: task characteristics, work context, and knowledge characteristics (Larkey, 1996; Morgeson \& Humphrey, 2006).

Table 2: Description of observed mistreatment practices in the sample cases

\begin{tabular}{|c|c|c|c|}
\hline & Practice & Description & Notes \\
\hline \multirow[t]{2}{*}{ Distributive } & $\begin{array}{l}\text { Excessive work } \\
\text { without compensation }\end{array}$ & $\begin{array}{l}\text { Employees were asked to work beyond } \\
\text { the regular workload without payment. } \\
\text { Sometimes, they are asked to skip breaks to } \\
\text { meet a deadline. }\end{array}$ & $\begin{array}{l}\text { Unfair distribution; procedural, } \\
\text { lack of definition regarding } \\
\text { workload }\end{array}$ \\
\hline & $\begin{array}{l}\text { Below minimum } \\
\text { wage }\end{array}$ & $\begin{array}{l}\text { Interns were hired as regular employees but } \\
\text { are paid at or below the minimum wage rate. }\end{array}$ & Unfair distribution \\
\hline \multirow[b]{2}{*}{ Systemic } & $\begin{array}{l}\text { Hostile work } \\
\text { environment-physical }\end{array}$ & $\begin{array}{l}\text { Interns were forced to work in inadequate } \\
\text { working conditions, such as unsecure and/or } \\
\text { dangerous conditions. }\end{array}$ & $\begin{array}{l}\text { Lack of a proper equipment } \\
\text { system and processes to ensure } \\
\text { workplace safety }\end{array}$ \\
\hline & Menial tasks & $\begin{array}{l}\text { Employees were only given opportunities to } \\
\text { handle menial tasks such as copying, filling } \\
\text { out forms, and cleaning. Interns were forced } \\
\text { to perform dubious tasks not mentioned in the } \\
\text { job description }\end{array}$ & $\begin{array}{l}\text { Systemically excluding young } \\
\text { talent from opportunity of learning }\end{array}$ \\
\hline \multirow[b]{2}{*}{ Procedural } & Misleading promises & $\begin{array}{l}\text { Promises were made but not delivered. Jobs } \\
\text { do not match with job descriptions. Interns } \\
\text { are promised a job after internship and do not } \\
\text { receive it. }\end{array}$ & $\begin{array}{l}\text { Lack of policy that defined } \\
\text { milestones for interns to achieve } \\
\text { changes in employment status }\end{array}$ \\
\hline & $\begin{array}{l}\text { Lack of } \\
\text { support }\end{array}$ & $\begin{array}{l}\text { Lack of liability coverage. No support } \\
\text { for professional activities. No training or } \\
\text { education. }\end{array}$ & $\begin{array}{l}\text { Unfair performance or process } \\
\text { expectations; Employees were } \\
\text { discriminated against while } \\
\text { performing same tasks based on } \\
\text { status }\end{array}$ \\
\hline Interactional & $\begin{array}{l}\text { Hostile work } \\
\text { environment - mental }\end{array}$ & $\begin{array}{l}\text { Interns were abused either verbally, mentally, } \\
\text { or sexually. }\end{array}$ & $\begin{array}{l}\text { Employees were treated with little } \\
\text { respect }\end{array}$ \\
\hline
\end{tabular}

Source: Harlos and Pinder (1999) 
The cases also provided very sparse information related to the two other dimensions, namely "social characteristics" or "outcomes and correlates," making data coding nearly impossible. To remedy this issue, only the three dimensions that were mentioned most frequently were include. Thus, while this analysis may not be the most comprehensive, it avoids the problem of missing variables by addressing how at least two dimensions of task description are related to mistreatment behavior.

The original WDQ has seven items under "task characteristics," four items under "work context," and five items under "knowledge characteristics." In this study, three items related to "autonomy," under "task categories," were merged into one item, labeled "autonomy." This was necessary because the sample cases did not provide detailed information that could be used to differentiate the types of autonomy. Based on the reported information relevant to these categories, each case was assigned a value of 1 for presence. Typically, researchers utilize a Likert scale rating to collect responses for an instrument like the WDQ, the data compiled here only follows a binary format, where 1 indicates that the case explicitly demonstrates the presence of an item, and 0 indicates no presence of the item. Thus, one case may have multiple $1 \mathrm{~s}$ if it involves multiple characteristics.

\subsection{Assessment Matrix for Recruit Mistreatment}

An assessment matrix may be produced by integrating the four dimensions, presented in Harlos and Pinder's (1999) mistreatment framework, most related to recruit mistreatment with the three theoretical frameworks discussed earlier. As evident from the discussion in the previous section, not all these four ethical dimensions are applicable to all cases. For example, there could be overtime work but not necessarily with menial tasks involved. However, entrepreneurs can use this matrix in their decision-making processes, which is consistent with the Hunt-Vitell model of ethical decision-making (Hunt \& Vitell, 1986). Thus, this study attempted to evaluate the potential ethical breaches in the four dimensions using the three theoretical frameworks. To this end, the deception involved in a given recruit hiring and treatment were considered using the deontological, utilitarian, and VBF perspectives, noting the key ethical conclusion in each cell. Next, the assessments were summarized for each ethical dimension and framework. A minus (meaningful ethical concern) or plus sign (little to no ethical concern) were used to capture the individual assessments. The matrix in the case of the use of college graduates as errand staff (see Table 3) suggests the greatest ethical concerns in the areas of misleading job descriptions and exploitation of recruits.
Note that extant studies have clearly demonstrated the significance informational justice for organizational justice (Lee \& Ha, 2020). It also reveals the least ethical concern based on the utilitarian framework and the greatest concern using the VBF. When weighed in this manner, the matrix shows that each practice is more ethically unacceptable.

Table 3 reveals that several ethical rules or universal principles were compromised while very few virtuous actions were facilitated. Though the cases revealed that the recruits conducted duties that were promised, and the netoutcome was far from negative, these practices did little to nothing to contribute to human virtue. The practices even casts doubt on the sincerity of the recruiting campaign. Some recruits suspected they were just used for the term projects they completed during the probationary period and abandoned after they were not needed anymore. Ethical breach from all three perspectives involved excess hours of work without proper compensation. First, it is a clear violation of the fair compensation principle as they failed to provide proper compensation for overtime work. Moreover, using after-hours labor without paying them negatively impacted the recruits, given the sizable opportunity cost they incurred. Human virtue is damaged rather than promoted by such practices.

Many cases revealed that the recruiting message was either unclear or confusing such that the recruits were led to believe that they were going to become full-time employees on completion of the probationary period. From a deontological perspective, this is a clear violation of the principle of transparency. Due to the unclear message, the hiring practice caused recruits to incur a significant opportunity cost. If they had known that the position was only for a trial period, they could have pursued other options. The presence of misleading promises that they were going to become full-time employees after the probationary period exacerbates the case. Whether it was in the form of a pep talk rather than a formal statement, such a practice is unethical in terms of the VBF, in that verbal signals were used to bait recruits to sacrifice other opportunities and endure a pitiful situation.

However, based on the utilitarian framework, the action outcomes or net effects of these misleading signals may be insignificant or nominal at best, leading to a fairly neutral assessment. In this case, the misleading promises did not make the situation worse. Finally, the fact that the practice had no issue with personal damage or harassment makes this dimension irrelevant. It should be noted that only one practice of mistreatment observed from the sample cases that stems from interactions with other individuals. When evaluated, the observed practices of talent treatment still appear to have serious ethical shortcomings. 
Table 3: Description of Work Design

\begin{tabular}{|c|c|c|}
\hline & & Characteristics of Work Design* \\
\hline \multirow[t]{5}{*}{ Task Characteristics } & Autonomy & $\begin{array}{l}\text { The job allows me to make my own decision on scheduling, making } \\
\text { decisions or having choices over the methods used. }\end{array}$ \\
\hline & Task Variety & The job involves doing a number of different things. \\
\hline & Significance & $\begin{array}{l}\text { The result of my work is likely to significantly affect the lives of other } \\
\text { people, in and out of organization. }\end{array}$ \\
\hline & Task Identity & $\begin{array}{l}\text { The job involves completing a piece of work that has an obvious } \\
\text { beginning and end. }\end{array}$ \\
\hline & Feedback & The job itself provides feedback on my performance. \\
\hline \multirow[t]{4}{*}{ Work Context } & Ergonomics & $\begin{array}{l}\text { The workplace allows for all size differences between people in } \\
\text { terms of clearance, reach, eye height, leg room, etc. }\end{array}$ \\
\hline & Physical Demand & $\begin{array}{l}\text { The job requires a great deal of muscular endurance, strength and/ } \\
\text { or physical effort. }\end{array}$ \\
\hline & Work Conditions & $\begin{array}{l}\text { The workers experience noise, high risk of accident, a great deal of } \\
\text { health hazards, and/or unclean environment }\end{array}$ \\
\hline & Equipment Use & The job involves the use of a variety of equipment. \\
\hline \multirow[t]{5}{*}{ Knowledge Characteristics } & Job Complexity & The tasks of the job are complicated. \\
\hline & Information Processing & $\begin{array}{l}\text { The job requires that I engage in the processing of a great deal of } \\
\text { information. }\end{array}$ \\
\hline & Problem Solving & The job requires unique ideas or solutions to problems. \\
\hline & Skill Variety & The job requires a variety of skills. \\
\hline & Specialization & The job requires very specialized knowledge and skills. \\
\hline
\end{tabular}

*simplified, merged and modified from original WDQ to be relevant for the purpose of current study, with maintaining the original intention

\section{Findings}

\subsection{Frequency Analysis}

First, patterns of the work characteristics that were specified in interviews were noted as best characterizing the work involved. When selecting up to three descriptors, the most frequently specified type of work, for both SMEs and large firms, were as follows:

- SMEs: task variety (22), work conditions (15), physical demand (13)

- Large firms: task variety (25), equipment use (24), feedback (21), job complexity (21)

An effort was made to identify the most frequent mistreatment behaviors based on the type of firm. The results were as follows:

- SMEs: below-minimum wage (14), menial tasks (12), excessive work without compensation (12)

- Large firms: below-minimum wage (17), menial tasks (15), excessive work without compensation (13)
The findings of this preliminary study demonstrate striking similarities in terms of mistreatment behaviors, with moderate differences in terms of the source of these behaviors. The young talent, in both SMEs and large firms, complained about their below-minimum wage rates. In both cases, individuals were not satisfied because they did not receive a chance to learn from serious professional tasks; rather they were assigned menial tasks. Most of them seemed to have worked overtime but did not receive proper compensation.

The differences were that young talent in large firms were involved in the use of equipment. Feedback was given about their performance, which lead to complications. The young talents in the SME context seemed to struggle with relatively poor working environments, mostly due to a high level of physical demands.

\subsection{Cluster Analysis}

First, Next, to gain more systematic insights into how different kinds of mistreatment behaviors are clustered 
together, a cluster analysis was conducted using the inventory of observations. Based on the Bayesian information criterion, a diagonal, equal volume and shape model (EEI) with three clusters (Fraley \& Raftery, 2002) was selected. To account for the ordered binary data (presence versus non-presence), a hierarchical clustering procedure was employed using squared Euclidean distances. The nearest neighborhood method was used as it provides the highest statistical power for a given data set. The three clusters were then characterized by the three mistreatment behaviors. The work characteristics appearing in most of the clusters are summarized in Table 4.

The cluster analysis showed a nearly even distribution of SMEs and large firms in two clusters (Clusters 1 and 3), but included the far more larger firms in Cluster 2, which was differentiated from the other two clusters by the presence of "menial tasks." The relationships among the clusters in terms of work design attributes are presented graphically in
Figure 1. Since Cluster 2 had the largest number of large firms, being characterized as having "job complexity" indicates that young talent may be more exposed to situations where they can perform tasks with complexity.

\section{Discussion}

The application of the proposed assessment matrix produced a couple of patterns. First, the deontological framework tended to produce the most rigorous assessment of recruiting practices. It was helpful in establishing the key moral principles to be considered when assessing a given recruiting approach. However, the relative severity of a given ethical violation was not very clear with this framework, and many of the ethical principle or rule violations cited using the deontological view seemed moderate to low in their severity. Thus, this framework was a good first hurdle.

Table 4: Cluster Analysis

\begin{tabular}{|c|c|c|c|c|}
\hline & Cluster 1 & Cluster 2 & Cluster 3 & Sum \\
\hline $\begin{array}{l}\text { Practice } \\
\text { (Top 3) }\end{array}$ & $\begin{array}{l}\text { - Excessive work without } \\
\text { compensation* } \\
\text { - No support* } \\
\text { - Below minimum wage }\end{array}$ & $\begin{array}{l}\text { - Menial tasks* } \\
\text { - Hostile work environment } \\
\text {-mental } \\
\text { - Misleading promises }\end{array}$ & $\begin{array}{l}\text { - } \text { Misleading promises } \\
\text { - Below minimum wage } \\
\text { - Hostile work } \\
\text { environment-mental }\end{array}$ & \\
\hline $\begin{array}{l}\text { Work characteristics } \\
\text { (Top 3) }\end{array}$ & $\begin{array}{ll}\text { - } & \text { Task variety } \\
\text { - } & \text { Work conditions } \\
\text { - } & \text { Equipment use }\end{array}$ & $\begin{array}{ll}\text { - } & \text { Task variety } \\
\text { - } & \text { Equipment uses } \\
\text { - Job complexity }\end{array}$ & $\begin{array}{ll}\text { - } & \text { Task variety } \\
\text { - } & \text { Physical demands } \\
\text { - } & \text { Work conditions }\end{array}$ & \\
\hline Number of SMEs & 14 & 9 & 3 & 26 \\
\hline $\begin{array}{l}\text { Number of large } \\
\text { firms }\end{array}$ & 16 & 19 & 3 & 38 \\
\hline Number of cases & 30 & 28 & 6 & 64 \\
\hline
\end{tabular}

* a behavior unique to the cluster

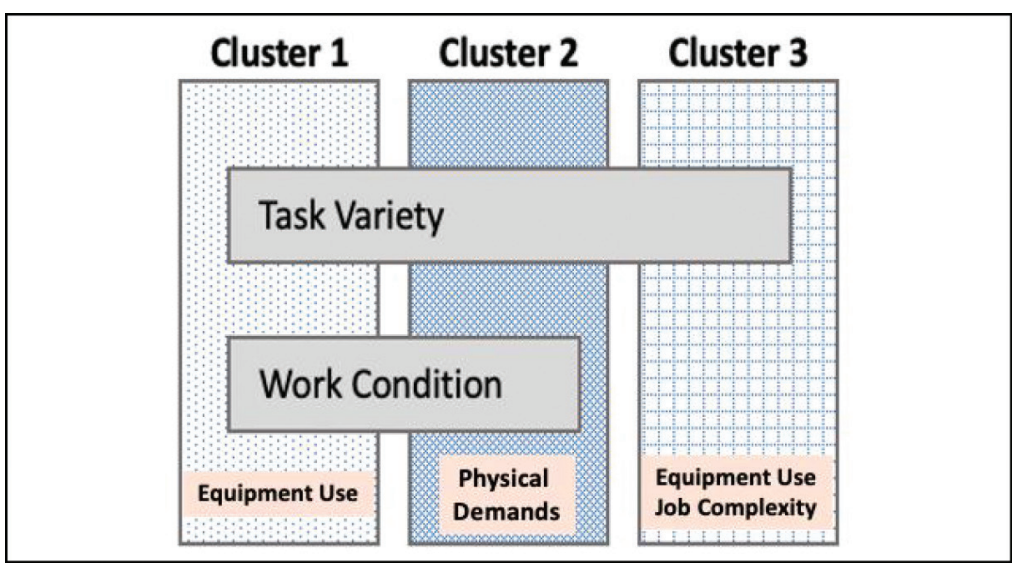

Figure 1: Shared and Unique Work Design Attributes by Cluster 
Alternatively, the utilitarian framework provided the most tolerant assessment of the examples. Specifically, within a given resource-constrained context, entrepreneurial firms were less likely to cause a massive impact with their recruiting campaigns. These campaigns also tended to be fairly short-lived. Moreover, the fact that most of the contracts were based on mutual agreement made any assessment of negative outcomes very difficult, even when there was an clear negative outcome. The challenge here was that one may be too quick to conclude that the ends justify the means. The ends in the example cases tended to be less negative in their impact, more than the evidence of high positive impact, although clearly there were recruiting campaigns that greatly benefitted the companies that implement them.

Regarding the VBF, it is interesting that our results suggested a parallel between the VBF and the deontological framework in the first two examples but generated different results for the other examples. The VBF is more contextual, i.e., even if an action does not violate a moral principle or rule, if that action violates a virtue in a given situation, the action fails to qualify as ethical. This point was best seen with the WeMakePrice example where there were no clear deontological violations, no illegal activities, but a virtue was being violated.

This finding is further consistent with Brenkert's (2009) argument that pointed out the limitations of a rule-based view of entrepreneurial ethics. He stated that the ethicality of entrepreneurial behavior is better assessed by validating whether an action promotes social virtue. This study supports this view and argues that, even if an action abides by rules or laws, firms should not stop assessing and continually checking whether an action promotes or violates a virtue of human society. Although deontology may be a good first hurdle and may provide a valid evaluation at times, it could also potentially mislead entrepreneurs when making ethical decisions. Alternatively, a virtue-based view provides entrepreneurs with a much wider and comprehensive framework to reach a valid assessment when making ethical decisions.

\subsection{Conclusion and Implication}

The creativity and imagination invested into recruiting campaigns, and their potential to benefit companies by using them at a relatively low cost, may lead entrepreneurs (and other firms) to overlook the critical ethical aspects of such campaigns. In the current study, three objectives were established to achieve a major goal, i.e., establishing a conceptual basis for theoretical development regarding talent misuse in the context of SMEs. The three objectives were: (1) to explore and build a list of unethical practices faced by young talent to highlight special attributes associated with the SME context; (2) to establish a new framework for this special context or refine the existing framework for employee mistreatment; and (3) to facilitate further discussion of unethical treatment of young talent within the context of SMEs.

To achieve the first goal, an attempt was made to develop a list of mistreatment behaviors by collecting and analyzing ethical dispute cases. Analysis of 64 cases of talent mistreatment, referred to as "passion pay" here, was conducted to present a conceptual basis for further investigation. The analysis observed seven different mistreatment behaviors under four categories of mistreatment practices. Next, for the second objective, this study proposed an integrative approach to assess these ethical elements. While the assessment remains subjective, it does offer the entrepreneur guidance to determine whether a given recruiting approach may be inappropriate from an ethical perspective. Ethical implications were discussed based on an assessment of three theories of ethics. Finally, this study adds to the literature of job design. Using the mistreatment behaviors observed from the case analysis, a cluster analysis was conducted, which further showed the emergence of three groups based on mistreatment behaviors. Additionally, the cluster analysis results imply that talent mistreatment may be rooted in job design, which is consistent with the findings of previous studies (Yoon, Kim, \& Eom, 2019). Organizational size may provide some contextual reason, but it was unclear as to what extent this quality interacts with job design. In conclusion, while it is premature to declare a correlation between organizational attributes and mistreatment behavior, this study makes a small step toward the advancement of ethical study in the field of entrepreneurship by providing a foundational basis for further investigations.

\subsection{Future Research and Limitation}

The Based on this study, a number of directions for future research can be suggested. While three general ethical frameworks were selected for this study, other approaches exist (Brady \& Dunn, 1995). The value of such frameworks in terms of justice, egoism, and social contracts should be assessed within any recruiting context, as they may help to clarify some of the conflicting conclusions obtained when the three frameworks were applied to a given recruiting approach. While this study relied on subjective assessments that were dichotomous in nature, measurement issues warrant more attention. There is a need for validated scales to measure how a recruiting action performs within each of our ethical dimensions and theoretical frameworks (e.g., Reidenbach \& Robin, 1990).

Second, it is necessary to investigate the source of mistreatment behavior in the context of different industry sectors. This study assumed that organizational settings might foster mistreatment behaviors. For example, firms in 
the knowledge-intensive sector always utilizes unique hiring strategies because obtaining critical human resources is very important to their early stages of survival and success (Jang, 2014; 2015).

Third, it is necessary to consider the company's perspective to evaluate the effectiveness of existing policies and established procedures. This could open up the possibility of another study that could examine applicability and limitations within the context of SMEs.

Finally, another strategy could be applied by taking a typology approach. It is largely accepted that there are discrete types of entrepreneurial ventures (Morris et al., 2015, 2018). Shedding light on the unique context of each type of organization in terms of talent mistreatment would definitely enhance understanding of the phenomenon.

This research has several limitations due to the premature nature of the topic discussed in this study. A major limitation is that, due to the relatively small number of samples, it was impossible to build an exhaustive list of mistreatment behaviors. The second limitation is rooted in the inherent limitations of case analysis. Since each case reflects the perspective of the interviewee, there is no way of verifying whether the mistreatment actually took place. As mentioned earlier, the severity of each issue also could not be measured. As a remedy to this issue, a survey-based study is currently under development. However, it is recommended to develop a strategy to verify the presence of mistreatment from both parties involved: the interns and the company.

\section{References}

Airaksinen, T. (1987). Moraalifilosofia. Finland: WSOY.

Bradburn, R. (2001). Understanding business ethics, London, UK: Continuum.

Boswell, W. R., \& Olson-Buchanan, J. B. (2004). Experiencing mistreatment at work: The role of grievance filing, nature of mistreatment, and employee withdrawal. Academy of Management Journal, 47(1), 129-139.

Brady, F. N., \& Dunn, C. P. (1995). Business meta-ethics: An analysis of two theories. Business Ethics Quarterly, 5(3), 385398. DOI: $10.2307 / 3857390$

Brenkert, G. G. (2009). Innovation, rule breaking and the ethics of entrepreneurship. Journal of Business Venturing, 24(5), 448-464.

Duncan, S. M. (1995). A primer of modern virtue ethics. University Press of America Lanham, MD.

Fraley, C., \& Raftery, A. E. (2002). Model- Based Clustering, Discriminant Analysis, and Density Estimation. Journal of the American Statistical Association, 97(458), 611-631.

Harlos, K. P., \& Pinder, C. (1999). Patterns of organizational injustice: A taxonomy of what employees regard as unjust. Advances in Qualitative Organizational Research, 2, 97-125.
Häyry, M. (1999). Three morals. In: T. Airaksinenand \& K. Kaalikoski (Eds.), Opin Filosofiaa, Filosofian Opit, Helsinki, Finland: Yliopistopaino.

Hunt, S. D., \& Vitell, S. (1986). A general theory of marketing ethics. Journal of Macromarketing, 6(1), 5-16.

Jang, Y. (2014). Dynamics of Fast Market Entrance for Young Entrepreneurial Firms Providing Products in Markets: Innovation, Organization and Entrepreneurs. Academy of Entrepreneurship Journal, 20(1), 75-98.

Jang, Y., \& Morris, M. H. (2015). The Ethics of Guerilla Behavior in Early Stage Firms. In: The Challenges of Ethics and Entrepreneurship in the Global Environment (pp. 57-78). Emerald Group Publishing Limited.

Jang, Y. (2016, January). Passion Pay? Ethics of Talent Exploitation by Entrepreneurial Ventures Focusing on the Case of WeMakePrice. In: United States Association for Small Business and Entrepreneurship. Conference Proceedings (p. FX). United States Association for Small Business and Entrepreneurship.

Katz, A. (2011). Virtue ethics and efficient breach. Suffolk University Law Review, 45, 777-798.

Kim, H. S., \& Lee, H. A. (2020). Associations among Procedural Fairness, Tax Compliance, and Tax Re-audits. Journal of Asian Finance, Economics, and Business, 7(7), 187-198. https://doi. org/10.13106/jafeb.2020.vol7.no7.187

Larkey, L. K. (1996). The development and validation of the workforce diversity questionnaire: An instrument to assess interactions in diverse workgroups. Management Communication Quarterly, 9(3), 296-337.

Ladkin, D. (2006). When deontology and utilitarianism aren't enough: How Heidegger's notion of "dwelling" might help organizational leaders resolve ethical issues. Journal of Business Ethics, 65(1), 87-98.

Lahdesmaki, M. (2005). When ethics matters-interpreting the ethical discourse of small nature-based entrepreneurs. Journal of Business Ethics, 61(1), 55-68

Lee, C., \& Ha, B. C. (2020). The Impact of Interactional Justice and Supply-Chain Collaboration on Sustainable SCM Performance: The Case of Multinational Pharmaceutical Firms. Journal of Asian Finance, Economics, and Business, 7(2), 237-247. https://doi.org/10.13106/jafeb.2020.vol7.no2.237

Lee, K. (2015). WeMakePrice Re-Hiring 11 Fired Assistants after Internet Backlash. Korean BizWire, Retrieved August 10, 2020 from: http://koreabizwire.com/wemakeprice-re-hiring-11fired-assistants-after-internet-backlash/27591

Meares, M. M., Oetzel, J. G., Torres, A., Derkacs, D., \& Ginossar, T. (2004). Employee mistreatment and muted voices in the culturally diverse workplace. Journal of Applied Communication Research, 32(1), 4-27.

Morgeson, F. P., \& Humphrey, S. E. (2006). The Work Design Questionnaire (WDQ): developing and validating a comprehensive measure for assessing job design and the nature of work. Journal of Applied Psychology, 91(6), 1321-1339. DOI: 10.1037/00219010.91.6.1321 
Morris, M.H.,Neumeyer,X.,Jang,Y.,\&Kuratko,D.F.(2015). Revisiting the entrepreneurial context: Types of ventures and associated identities. In: Academy of Management Proceedings (Vol. 2015, No. 1, p. 14659). Academy of Management.

Morris, M. H., Neumeyer, X., Jang, Y., \& Kuratko, D. F. (2018). Distinguishing types of entrepreneurial ventures: An identity-based perspective. Journal of Small Business Management, 56(3), 453-474.

Olson-Buchanan, J. B., \& Boswell, W. R. (2008). An integrative model of experiencing and responding to mistreatment at work. Academy of Management Review, 33(1), 76-96.

Passion Pay. (2015, January 13). Employers should stop exploiting young labor. Korea Herald. Retried August 10. 2020 from: http://www.koreaherald.com/view.php?ud=20150113000343

Park, S.-S. (2015). WeMakePrice faces probe over abuse of recruits. Korea Times, Retrieved August 10, 2020 from: http://www. koreatimes.co.kr/www/news/biz/2015/02/123_171521.html

Reidenbach, R. E., \& Robin, D. P. (1990). Toward the development of a multidimensional scale for improving evaluations of business ethics. Journal of Business Ethics, 9(8), 639-653.

Velasquez, M. (2000). Globalization and the Failure of Ethics. Business Ethics Quarterly, 10(1), 343-352. DOI: $10.2307 / 3857719$

Velasquez, M. G., \& Velazquez, M. (2002). Business ethics: Concepts and cases (Vol. 3). Upper Saddle River, NJ: Prentice Hall.

Weil, S. (2003). The need for roots: Prelude to a declaration of duties towards mankind. Abingdon, UK: Routledge.

Weisberg, A., Pfleiger, A., \& Friedberg, J. (2007). Undercover agency the ethics of stealth marketing. In: L. Burkhart, J. Friedberg, T. Martin, K. Sharma, \& M. Ship (Eds.), Confronting information ethics in the new millennium. Leeds School of Business.

Whetstone, J. T. (2001). How virtue fits within business ethics. Journal of Business Ethics, 33(2), 101-114.

Yoon, K. H., Kim, B. Y., \& Eom, J. G. (2019). The effects of job crafting on career success of multinational corporations' employees. Journal of Asian Finance, Economics and Business, 6(4), 213-225. https://doi.org/10.13106/jafeb.2019.vol6.no4.213 